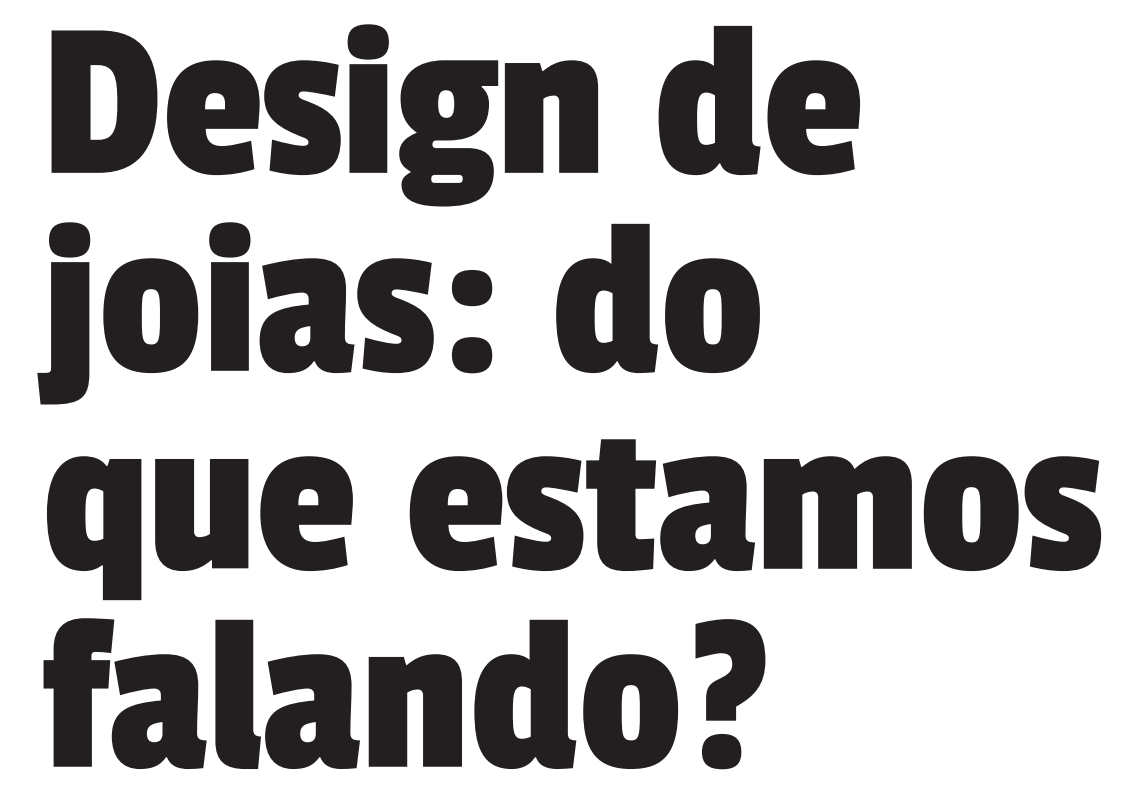

Engracia Maria Loureiro da Costa Llaberia é Doutora e Mestre em Design pela Universidade Anhembi Morumbi. Desenhista Industrial graduada pela Escola Superior de Desenho Industrial (ESDI/ UERJ). Bacharel em Comunicação Social, Publicidade e Relações Públicas e graduada em Tecnologia em Design de Interiores pela UNIP/SP. Docente da Universidade Anhembi Morumbi de 2008 a 2016, onde foi Coordenadora do Curso Superior de Tecnologia em Design de Produto: Joias. (2009-2011). Designer de joias desde 1986, atuando junto à industria e pequenas empresas, e marca própria (Officina di Design). É, desde 2007, Diretora de Design da Associação dos Joalheiros do Estado de São Paulo, AJESP. <gracia.costa02@gmail.com> ORCID: 0000-0003-0276-7726
Resumo Este artigo vem propor uma reflexão a partir de considerações sobre o design de joias e o uso do termo design na joalheria nas diversas acepções com entendimentos distintos no processo de criação e produção joalheira, até sua inserção no campo do Design. Procura-se mostrar como a adoção no português deste termo da língua inglesa, com traduções de conotações amplas, tem permitido uma sobreposição de atividades tão distintas relacionadas à joalheria quanto são as de desenhar criativamente, fazer a joia, até a projetá-la sob a perspectiva de produto de produção industrial, utilizando métodos do Design no projeto de criação e desenvolvimento de artefatos, seja para uma única peça ou para uma coleção para empresas. Trata-se, aqui, de buscar entendimento de modo a criar parâmetros para a prática da profissão de designer de joias no setor joalheiro, tanto no segmento de materiais preciosos como na produção industrial de folheados e bijuterias.

Palavras chave Design, Design de joias, Arte joalheira, Joalheria artesanal. 


\title{
Jewelry design: what are we talking about?
}

\begin{abstract}
This article proposes a reflection based on considerations about jewelry design and the use of the term design in jewelry with different meanings and different understandings in the process of creation and production of jewelry, until its insertion in the field of Design. It intends to show how the adoption in Portuguese of this term from the English language, with translations of wide connotations, has allowed an overlap of activities distinctly related to jewellery as to draw creatively, jewellery manufacture, or even to design under the industrial production perspective, using Design methods in the creation and development of artefacts, either for a single piece or for a collection for companies. Here, the matter is about understanding, in order to create parameters for the practice of the jewellery designer profession in the jewellery sector, both in the segment of precious materials and in the industrial production of gold plated and costume jewels.
\end{abstract}

Keywords Design, Jewelry design, Jewelry art, Artisanal jewelry.

\section{¿ Diseño de joyas: de qué estamos hablando?}

Resumen Este artículo propone una reflexión basada en consideraciones sobre diseño de joyas y el uso del término diseño en joyería con diferentes significados $y$ diferentes entendimientos en el proceso de creación y producción de joyería, hasta su inserción en el campo del Diseño. Se busca mostrar cómo la adopción en portugués de este término del idioma inglés, con traducciones de connotaciones amplias, ha permitido una superposición de actividades tan distintas relacionadas con la joyería como lo son diseñar creativamente, hacer joyas, incluso diseñarlas bajo la perspectiva del producto de producción industrial, utilizando métodos de Diseño en la creación y desarrollo de artefactos, ya sea para una sola pieza o para una colección para empresas. Aquí, se trata de buscar el entendimiento para crear parámetros para el ejercicio de la profesión de diseñador de joyas en el sector de la joyería, tanto en el segmento de materiales preciosos como en la producción industrial de chapas y joyas.

Palabras clave Diseño, Diseño de joyas, arte joyera, joyería artesanal. 


\section{Introdução}

Design de joias é campo de conhecimento específico, que envolve diversas variáveis relacionadas à criação e produção de artefatos, e na contemporaneidade é uma área de atuação que tem sido assim identificada, de modo geral equivocado, em atividades que vão desde a elaboração de desenhos criativos até a confecção de joias por processos artesanais, em sua maioria únicas, bem como na produção industrial. Este artigo aborda o design de joias em sua prática profissional, e propõe uma reflexão acerca da denominação das atividades a ele relacionadas e da dificuldade em se ter definidas suas competências e as habilidades necessárias, particularmente quando se relaciona a empresas do setor joalheiro, no momento da contratação de um profissional para o desenvolvimento de produtos.

A experiência junto à Associação dos Joalheiros do Estado de São Paulo, proporcionou a oportunidade de analisar os diversos lados dessa questão, a partir de informações de empresários que contratam designers, assim como de designers que criam para empresas, além do contato também com profissionais de modelagem e equipes de produção de empresas com produção seriada e, ainda, artífices joalheiros que criam e produzem suas próprias coleções. Considera-se aqui, também, a observação em relação ao público, para quem a projetação industrial na joalheria é desconhecida, levando-se em conta o desserviço da mídia que coloca sob a mesma denominação toda e qualquer atividade de criação joalheira como design de joias. Assim, seria possível definirmos as fronteiras entre as atividades que assim são denominadas?

Observou-se que a principal questão está no fato de que ao se apresentarem como designers, os profissionais mostram atividades de tal modo diversas, a exemplo de que os que desenham, seja manualmente ou no desenho digital, em sua maioria desconhecem as técnicas do fazer da joalheria e não necessariamente dominam a prática projetual do design, assim como entre aqueles que a confeccionam, que também se apresentam como designers, com técnicas de ourivesaria, modelistas, também não necessariamente dominam o desenho ou mesmo são criativos. Estes dominam o ofício da joalheria, mas não criam, executam projetos de terceiros. E há, ainda, os que trabalham com montagem de objetos de adorno, com técnicas de artesanato em sua maioria, tal como a joia feita em fios de palha, madeira e pedras semipreciosas, contas, sementes, entre outros, em arranjos com uma estética contemporânea, também se apresentando como designers. Assim como há os que elaboram formas livres, como no fazer da arte. Há, naturalmente, também, os que possuem conhecimento de projeto, e criam joias para empresas ou para sua própria marca, a partir do desenvolvimento do produto em todas as suas etapas projetuais.

Assim, todos se intitulam designers, indiscriminadamente, mas com expertises e habilidades em atividades bem distintas. Nesse momento, essa identificação e classificação são necessárias para o setor em nome de sua profissionalização. 
O design é uma atividade que envolve capacidade técnica e artística, e reúne conhecimentos multidisciplinares e interações interdisciplinares, cuja complexidade o distância do entendimento pelo senso comum, cotidiano, que o traduz basicamente como todo e qualquer desenho ou forma.

Desse modo, o artigo busca apresentar as diferentes acepções e aplicações do termo design na joalheria, considerados todos os seus segmentos, como de o materiais preciosos, o de folheados e o de bijuterias, como forma de propor uma reflexão aos diversos atores nas diferentes atividades e etapas do processo de produção joalheira de modo a entender e valorizar a profissão, e se possa, então, responder: afinal, do que se está falando quando se trata do design de joias?

\section{Design como falamos}

A imprecisão do conceito vem do fato de a palavra design ter ganho diversas acepções vindas de traduções que foram sendo incorporadas a partir de usos coloquiais e que envolvem todo tipo de desenho (até o de sobrancelhas), ou a forma de qualquer coisa, objeto ou artefato. Essa falta de exatidão que ainda o acompanha no linguajar cotidiano traz mais prejuízos profissionais do que agrega valor ao campo, popularizando-o.

Mas tecnicamente traduz-se design como projeto, enquanto método, e o modo de pensar do designer, que pode ser aplicado a produtos, materiais ou virtuais, e também a serviços, em gestão e planejamento estratégico como no design thinking. E é esse "modo de pensar" que delineia a prática do design e o diferencia de outras áreas criativas como o artesanato, a artesania e a arte. Esse modo de pensar traz implícita a ideia da adoção de um método ou métodos de desenvolvimento de um produto.

Nesse ponto podemos evocar Wittgenstein (SILVA, 2020), entendendo os jogos de linguagem que são pertencentes a contextos determinados e, portanto, os atores nesse universo específico lidam com as palavras com significados por eles compreendidos, nascidos de sua vivência:

\footnotetext{
Wittgenstein pretende acentuar, com o conceito de jogos de linguagem, que a partir de diferentes contextos seguem-se diferentes regras de uso das palavras.

Essa mudança coloca a pragmática como anterior à semântica, ou seja, o uso da linguagem em contextos determinados acima de seu significado estabelecido, pois o significado das palavras e frases só pode ser resolvido pelo uso que se faz delas em contextos pragmáticos.
}

Dessa forma, os que participam do que podemos chamar de comunidade linguística, são os que entenderiam o significado de certas palavras dentro de determinados contextos. No entanto, a comunidade que atua em joalheria não necessariamente tem os conceitos de design de forma clara. 
Em sua maioria o traduzem pelo senso comum, pela linguagem popular. A joalheria é uma área na qual surgem novos interessados constantemente, pela aparente facilidade que há em lidar com objetos de adorno, seja pela necessidade de ter opções para o mercado de trabalho, como para empreender criando suas próprias marcas. Mas chegam à joalheria em grande número originárias de áreas distantes do Design.

Mas estamos aqui falando desse campo de conhecimento, que envolve a preparação de profissionais, não só na joalheria, mas em áreas como o Gráfico, o Digital, a Moda e Interiores, esse como a primeira profissão regulamentada na área do Design. E a joalheria não pode criar um tipo de "universo paralelo" em relação à conceitos e definições inerentes à prática do design, sendo alguns fundamentais para que haja entendimento entre todos.

A principal questão talvez esteja na falta de reconhecimento e regulamentação profissional ao que se acrescenta a fala de Lucy Niemeyer (2007, P. 27): "A palavra design permaneceu sem uma denotação específica no Brasil, não particularizando a profissão ou o seu conceito."

E como comenta Luis Antonio L. Coelho na apresentação do livro "Conceitos-chave em design" (2008):

Não há como discutir qualquer matéria sem um denominador terminológico comum. Um campo do saber se delineia a partir da identificação de seus termos básicos, de seu jargão, enfim, de sua base discursiva. Não há disciplina que não identifique seus termos operacionais.

Como campo de conhecimento, o Design de joias exigiria maior rigor técnico na conceituação de sua prática, de modo a propiciar o aprofundamento dos estudos na área. Cabe destacar que, à época da aprovação pelo Ministério da Educação, MEC, do curso tecnólogo em design de joias na Universidade Anhembi Morumbi, foi indicado que seu registro fosse feito como "Design de produto: joias", o que atrela sua prática a essa área específica do Design.

Este rigor, no sentido de exatidão, precisão, é necessário e exigido em outras áreas de conhecimento, tal como a Filosofia e o Direito, em que o uso de determinada nomenclatura muda completamente o sentido do que se discute. Um exemplo comum, as palavras "roubo" e "furto", que no direito configuram situações bastante diversas e no uso popular são sinônimos.

\footnotetext{
A linguagem do advogado, do médico, do comerciante, do político, do mestre-escola, etc. (...) diferenciam-se evidentemente não só pelo vocabulário: elas implicam determinadas formas de orientação intencional (...), são carregadas de conteúdos determinados, concretizam-se, especificam-se, impregnam-se de apreciações concretas, unem-se a determinados objetos, a âmbitos expressivos de gêneros e expressões. (...) Deste modo, em cada momento da sua existência histórica, a linguagem é grandemente pluridiscursiva (BAKHTIN, 1988, apud PIMENTEL, 2015).
} 
Assim, esse rigor técnico, profissional, seria também desejável em uma área que vem crescendo e se desenvolvendo, como é o Design de joias. Não havendo até aqui uma conceituação efetiva, permite-se que toda e qualquer atividade relacionada à criação em todos os segmentos da joalheria (em materiais preciosos, como em folheados e bijuterias) e das diferentes atividades nelas envolvidas, sejam anunciadas como design de joias e, naturalmente, seus criativos e artífices como designers de joias.

Mas essa questão se relaciona àquela apresentada inicialmente $\mathrm{e}$ que se refere à tradução da palavra design para o português, o que talvez possa ser explicado pelo que comenta Ana Mae Barbosa:

Entendamos aí a palavra desenho como design, pois em português só temos uma palavra para designar tanto desenho como 'Arte', como desenho como 'projeto ligado à indústria, comércio, moda, publicidade'. Só na década de 1960 começamos a usar a palavra Design, em inglês mesmo, para designar a última categoria mencionada (BARBOSA, 2015).

Conclui-se, assim, que ao traduzir-se, desenho para design ou design para desenho, observa-se a questão inicial de não se dispor de palavras adequadas em português para designar corretamente diferentes campos de conhecimento e prática, porque tal como design, a palavra desenho também permite diferentes entendimentos.

Traduzir diretamente para desenho tornou-se o mais comum, haja vista exemplos como "design de sobrancelhas", como sendo o seu desenho (desenho de sobrancelhas?), e design de unhas, fazendo referência a motivos decorativos sobre elas, e que até estaria correto se esse se referisse às unhas postiças já vendidas em diferentes formatos e cores, configurando, aí sim, um produto resultante de um projeto de design de unhas para a indústria.

Ana Mae Barbosa destacou em aula o papel da cultura visual na ampliação do uso do termo design para situações que não lhe caberiam, mas que passaram a ser usadas popularmente, rompendo os limites de sua própria conceituação.

Nesse sentido, o desenho na joalheria tem um significado mais utilizado em um sentido de criação, em traços manuais ou digitais, mas que não envolve necessariamente métodos projetuais.

No entanto, o desenho no design é parte do processo do projeto, e é dele uma das ferramentas, e não ele mesmo, o que seria um entendimento simplista frente ao que é de fato a complexidade do design enquanto atividade projetual.

Assim, a terminologia comumente usada no universo joalheiro hoje, por exemplo, faz referência ao "design de uma coleção de joias" para designar a criação de um conjunto de peças por meio da representação gráfica de ideias criativas, em ilustrações, sem desenho técnico e especificações, como 
tem sido o mais comum na apresentação dos designers de joias às empresas, e não o desenvolvimento de um conjunto de peças a partir de premissas de projeto de design. É dessa forma que a grande maioria dos "designers de joias" se apropria do conceito de design para se referir ao seu trabalho.

Como exemplo, a frase dita em português, "esse design pode ser modificado, sem comprometer o design proposto", nos dá noção da dimensão desta questão na nossa língua, da qual podemos compreender: "esse desenho pode ser modificado, sem comprometer o projeto do produto" que era o que quem a pronunciou quis dizer, quase que traduzindo diretamente do inglês, que seria: "this design can be modified without compromising the design".

Mas a palavra desenho pode aferir um significado, sim, de projeto, quando quem a usa o faz na colocação adequada, em contextos precisos. Como comenta João de Souza Leite (2013): “[...] em nossos dias, desenho passa a ser claramente a tradução mais explícita de design, em seu sentido de projeto e configuração."

Como podemos observar, utilizar desenho como projeto depende de contextualização e de conhecimento prévio, logo pertence a uma comunidade linguística específica, porque a palavra desenho também pode ser usada em muitas situações, nas quais não necessariamente o projeto está envolvido. Se a observarmos, são desenhos os rabiscos das crianças, como são desenhos os de sobrancelhas, são desenhos os de humor, as caricaturas, são desenhos os rascunhos aleatórios em guardanapos, são também desenhos os rascunhos de ideias, são desenhos os grafites nas paredes, assim como são desenhos os esboços, croquis e o desenho técnico, principal ferramenta do projeto de design. Afinal, é através dele que são feitas as especificações e detalhamentos dos artefatos. O projeto traz maiores responsabilidades ao desenho, porque pressupõe por meio dele as especificações que são resultado de etapas de pesquisa e análise.

\footnotetext{
O desenho artístico e técnico é a expressão do design. O Design Industrial, pressupõe uma mistura inteligente de arte e técnica, onde a solução proposta para cada objeto atende às necessidades do consumidor, cumpre a função idealizada e está de acordo com as normas ambientais e de segurança (LARICA,2006).
}

E o desenho industrial, o design, é uma atividade que envolve multidisciplinaridade e interdisciplinaridade, tal como lembrou Claudio Lima Ferreira sobre a palestra de Aloisio Magalhães na ESDI, em 1977, quando destacou que o design "envolve a complexidade de vários saberes" (FERREIRA, 2014)

E aqui cabe destacar que a ênfase do que trata esse artigo está nessa acepção do termo design, que mais do que desenho apenas, ou a configuração da forma, traduz uma atividade profissional que insere o desenho e a configuração da forma como partes integrantes da prática projetual. 
E o projeto envolve muitas variáveis, bem como diversos elementos que definem parâmetros para seu desenvolvimento.

Para realizar pesquisa ou projeto em design, é necessário conhecer as teorias que o embasam, os métodos de projetação que emprega e familiarizar-se com as diferentes situações de contextualização em que é ou pode ser utilizado. (NOJIMA, 2006).

Então caberia aqui definir também projeto. Nesse contexto projetar é mais que uma planificação. Para João de Souza Leite:

O projeto em design se configura como o processo de elaboração do conjunto de documentos necessários à execução de qualquer objeto, seja este de qualquer dimensão ou característica, tendo sido desenvolvido a partir da construção do problema em multiplicadas derivações, por exemplo: quanto a seu significado, quanto a aspectos da produção, quanto a múltiplos aspectos de uso e funcionamento, quanto ao impacto no meio ambiente, quanto às ferramentas projetivas, entre outras tantas, inclusive os aspectos subjetivos de quem projeta.

A articulação de todos os elementos que estruturam um projeto de design habilita, então, os profissionais a atenderem demandas específicas.

Considerando o conceito de design como um todo, contamos com a agravante de termos livros traduzidos sem esse rigor em relação à definição, não só em publicações de joalheria, em que tem sido fácil observar a tradução inadequada de design para desenho ou forma ao invés de projeto, assim como projeto no lugar de desenho ou de forma, entre outras.

E em relação à joalheria, especificamente, talvez o maior problema esteja no fato de que há poucas publicações com respaldo de pesquisa acadêmica, o que exigiria assertividade nas traduções ou no emprego preciso das palavras. No entanto, a maior parte da bibliografia existente foi escrita por profissionais a partir de sua prática, o conhecimento tácito, não necessariamente relativo a disciplinas específicas.

A adoção popularmente desta nomenclatura, de forma genérica, tem levado o setor joalheiro a enfrentar grandes mal entendidos, tanto na discussão teórica da prática joalheira, como, e principalmente, na identificação dos profissionais no momento de uma contratação por uma empresa para desenvolvimento de produtos, bem como para sua formação.

Destaque-se que a visão estratégica, que é inerente ao design contemporâneo, não foi ainda nem mesmo percebida pela grande maioria das empresas, que apenas contratam o criativo, e não o profissional de desenvolvimento de produto, o designer. 
O que se apresenta como um problema na área da joalheria é que, nas diferentes acepções possíveis do termo design, todas vêm sendo usadas, faladas, em contextos nos quais, muitas vezes, qualquer uma delas caberia, mas referindo-se a atividades diversas, levando a um grande desentendimento. As traduções de design como desenho, forma, ou ainda, projeto, são possíveis, desde o apenas desenhar, ao modelar em metal, cera, ou em programas digitais, até o projetar com algum método de design, tendo como consequência primeira a impossibilidade de definição das atribuições do designer, particularmente na indústria joalheira, para além da criação.

$\mathrm{E}$, nesse contexto, temos observado que muitos dos profissionais que lidam em diferentes frentes com a joia, como os de desenho criativo, os modelistas, sejam ourives ou operadores de programas digitais de prototipagem, e os designers de produto, se apresentam indistintamente como "designers", uma vez que, não havendo regulamentação para a profissão, que a princípio foi traduzida como desenho industrial, a identificação das atribuições profissionais é hoje praticamente inviável.

Entende-se que não seja a questão da adequação da tradução restrita à joalheria, a discussão sobre a definição para o termo design é presente desde mesmo a adoção dessa nomenclatura como desenho industrial, que identifica o profissional de design, o designer, sobre o que comenta Lucy Niemeyer (2007):

\footnotetext{
A palavra design permaneceu sem uma denotação específica no Brasil, não particularizando a profissão e seu conceito. No momento há o emprego do termo design em áreas nas quais não há um trabalho conceitual e de projeto.
}

Então a questão é mais ampla, e trata do design e de sua linguagem, como forma de termos uma cultura projetual que defina o campo e sua atuação. Buscando no pensamento de Krippendorf (2000) quando afirma:

\footnotetext{
Meu objetivo é nada menos que propor uma mudança de ser falado por uma linguagem, para falar uma linguagem de forma consciente; de falar de uma maneira própria do designer, para forjar um discurso do design capaz de criar o que desejamos que o design seja; de praticar o design, para reprojetá-lo da maneira que ele seja engajado na melhoria de práticas projetuais.
}

Design de joias deve ser visto como uma das especializações do design, dentro do design de produto, e como tal, entende-se como atividade projetual, sob os mesmos parâmetros e discurso do design como um todo. 


\section{Design como desenho}

Como já visto, na tradução mais direta e popular para o português, design é entendido como desenho. Destaque-se que não é a tradução mais apropriada, uma vez que o desenho tem palavra correlata no inglês: "drawing". Essa foi uma questão já tratada por diversos autores, destacando Ana Mae Barbosa (2015), em seus importantes estudos sobre o desenho.

No universo joalheiro, através da história, o desenho teve papel fundamental em muitos de seus processos de produção, servindo como base para moldes, como referência de detalhamento técnico ou mesmo como representação artística.

Cellini teria sido um dos primeiros na sua utilização para comunicação com a produção, que Richard Sennett lembra como tendo sido a partir dele a interação entre o desenho de criação e a produção pelos ourives, iniciando uma nova fase no fazer da ourivesaria, citando T. Heslop que chamou a atenção para o fato de que o naturalismo na ourivesaria obrigou a adoção do desenho na confecção de joias:

As imagens de Cellini em ouro são uma consequência: desse processo: trata-se de um "novo" tipo de ourivesaria, em parte simplesmente por incorporar no trabalho de metal uma outra prática artesanal, a do desenho (SENNETT, 2012).

As joias ao longo da história, tiveram entre seus criadores, em geral, artistas ourives que dominavam o desenho, como, por exemplo, Botticelli, que no início de sua carreira trabalhou em um ateliê de joias, aprendeu ourivesaria e onde começou também a desenhá-las, e só posteriormente seguiu seus estudos em pintura com Filippo Lippi. Lalique que aprendeu ourivesaria e posteriormente passou a desenhar para várias joalherias. Mucha, um dos maiores nomes do Art Nouveau, pintor e desenhista, fez belos desenhos, como os confeccionados por Georges Fouquet, um dos mais importantes nomes da joalheria. E não raro encontramos em telas consagradas, como no Renascimento, detalhes de joias nas figuras representadas. Essa tem sido uma importante fonte de pesquisa histórica e de estilos

A figura do designer de joias, especializado em design de produto, vai ganhar destaque nas últimas décadas, a partir de novas tecnologias e do aumento da produção industrial. Esse entendimento de projeto se fez então necessário com o aumento da demanda de consumo e a necessidade de atendimento a públicos e mercados muito distintos, nos quais a expertise do designer passou a ser necessária, para além do aspecto criativo.

De um modo geral, em uma leitura mais superficial, muitos dos que se apresentam como designers de joias, se caracterizariam mais como o profissional de criação, o criativo, que apresenta seus trabalhos basicamente através do desenho. Esses são vistos como possuidor de sentido estético 
e artístico, mas, para a percepção de alguns, com falta de conhecimento técnico em relação a processos produtivos. Muitos empresários costumam repetir a máxima de que "o papel aceita tudo", como clara referência a esse desconhecimento quanto às possibilidades e as restrições na produção, fazendo com que, mesmo após a aquisição de desenhos por parte das empresas, um grande número deles seja arquivado pela inviabilidade técnica de sua execução. Infelizmente, essa visão equivocada do profissional do design, principalmente de como se identifica o designer de joias, tem comprometido seriamente a profissão no setor.

De toda forma, o desenho tem um lugar dentro das diferentes etapas do desenvolvimento de uma joia, ainda que não considerado o projeto de design enquanto método no desenvolvimento de produto. Isso porque o desenho possui diferentes graus ou níveis de elaboração, do mais simples ao mais detalhado, até os que são feitos com técnicas artísticas.

O idioma inglês adotou cotidianamente a palavra sketch para todos esses níveis de elaboração de desenho que em português tentamos identificar tecnicamente como rascunhos, esboços, desenho técnico e ilustração, embora se observe o uso diferenciado de roughs para rascunhos, tal como aponta Henny Favaro (2013). Os desenhos chamados também de sketches no Brasil são os da fase de esboços ou croquis, que possuem aplicação em fases distintas na Arquitetura e no Design de Interiores, pois têm função diferentes nos projetos de design de joias.

Esses tipos de desenho, como os projetivos e não-projetivos, e os definidos pelo grau de elaboração e pormenorização, foram assim identificados na NBR-10647, que está em revisão nesse momento (ano de 2020), pela Comissão de Estudo Especial, CEE-237, na ABNT, Associação Brasileira de Normas Técnicas.

o que se observa na joalheria é que o desenho, em todos esses níveis de elaboração, desde os rascunhos, esboços, o técnico ou a ilustração artística, veio sendo entendido como o design em si, especialmente devido ao fato do desconhecimento, pela maioria, da estrutura de um projeto de design ou, melhor dizendo, do design como atividade de projeto de produto de joalheria. E nesse caso, o desenho é dele uma das ferramentas, um dos recursos de representação gráfica, utilizado nas diferentes etapas de desenvolvimento de uma ideia.

\section{Design como forma}

Traduzir design apenas como a forma de um artefato, pressupõe o conhecimento do processo do qual resulta, após etapas de pesquisa e análise. Mas caberia aqui a questão no que se refere à aplicação da definição da configuração no projeto de design de joias, um universo eminentemente artístico, e sua função entendida como sendo a de adornar. Ao considerarmos que o design como conceito esteve por muito tempo atrelado a soluções formais racionais e funcionais, nas últimas décadas se viu frente a novos 
paradigmas que o levaram para a perspectiva dos aspectos emocionais e simbólicos na relação entre produto e usuário. Sotssass, marcou uma mudança desse paradigma ao modificar a configuração da máquina de escrever Olivetti, tirando-a de um objeto que tinha características formais apenas ligadas à sua função para um objeto com outros apelos através da cor e da forma. Essa mudança se relaciona a uma visão mais centrada no usuário. E o design, contemporaneamente, está voltado essencialmente ao usuário, como o estudo da "semântica do produto" apontado por Klaus Krippendorf (2000). 0 atendimento de demandas e necessidades específicas de um público determinado se tornou o principal objetivo do design. Na joalheria essa relação é indissolúvel. E isso talvez defina melhor o que se quer apresentar como sendo imperioso dentro da conceituação de projeto de design de joias. E aqui cabe uma discussão em relação ao que pontua Dijon de Moraes ao apontar que:

A estoica tentativa "Ulmiana" de conceber um formato de trabalho, através da instituição de equipes próprias de designers dentro das empresas, seguindo por vez uma metodologia lógica e objetiva para a concepção dos produtos industriais, foi substituída pelo design de assinatura, onde vem valorizado o talento individual e a poética própria de cada profissional, o que de certo modo aproxima hoje os designers do modelo de trabalho praticado pelos artistas.

Por esse modelo, a personalidade do designer se sobrepõe às características e demandas do usuário, o que traz uma contradição em si mesma, na medida em que o design deixa de se voltar para um usuário identificado para ser uma expressão pessoal. Essa mudança de protagonismo nos projetos de design é a principal contradição no discurso do design autoral, se considerarmos como Design enquanto campo de estudo relacionado à atividade de projeto. Só teria sentido, aqui, se design estivesse sendo usado dentro da linguagem popular, em que design é o "fazer a forma". E nesse aspecto, retoma-se o comentário de Dijon de Moraes (2020):

\footnotetext{
O sempre atento Gui Bonsiepe (1934) nos provoca para a necessidade de o design haver contornos próprios ou pelo menos de mais fácil identificação como uma disciplina de cunho projetual. Segundo Bonsiepe, assim procedendo, o design teria mais chances de ser reconhecido como campo de conhecimento próprio e distinto de outras atividades correlacionadas.
}

Uma coleção de peças de adorno, quando desenvolvidas para uma empresa, não carrega consigo a personalidade do designer, mas o perfil das características do público a que ela pretende atender, identificado em pesquisa inicial no projeto. 
Este ponto talvez defina melhor uma diferença no processo criativo do designer de produto e do artífice da joalheria autoral, por exemplo. Nessa produção as formas nascem de elaboração e escolhas pessoais, e o público responde a ela por afinidade ao estilo.

Tendo criado joias dentro das duas possibilidades de processos, a autora deste artigo, como desenhista industrial, teve a oportunidade de projetar joias para empresas, de pequeno a grande porte, em escala industrial, bem como, por ter sido proprietária de duas lojas, pode desenvolver joias autorais, sendo que o processo de criação tinha conotação mais pessoal, com traços e estilo próprios, enquanto as joias para empresas foram criadas para atender públicos que talvez não se alinhassem a seu estilo, mas que foram desafios a serem superados como designer. Tal foi o caso do desenvolvimento de uma coleção para a empresa Avon, que teve a primeira edição no lançamento com 50 mil peças vendidas. Nesse momento, as peças de bijuterias criadas foram projetadas para atender ao público específico da empresa, na faixa de preço por eles determinada, com os materiais e processos possíveis dentro dos parâmetros dados para essa coleção. Não eram criações que poderiam traduzir um estilo pessoal como designer, mas que se ajustavam tanto à imagem da modelo que deu nome à coleção, Luisa Brunet, e as características que as aproximariam do público da empresa. Outras duas coleções foram desenvolvidas para a empresa dentro do mesmo direcionamento.

Entende-se, assim, que a racionalidade e a funcionalidade na joalheria se dão, então, em outras etapas do processo, envolvendo a criação definida como solução a condicionantes para a produção.

\footnotetext{
Para os profissionais de design, criar significa que há um problema que primeiro precisa ser identificado para então ser resolvido. Uma vez identificado o problema, o designer segue um processo lógico, que ele aplica a cada fase do projeto. Esse processo é uma habilidade aprendida que corresponde a técnicas, e não um talento misteriosamente inerente a alguém. (MOZOTA, 2011, p.27)
}

Destaque-se aqui um ponto fundamental: em projetos de design a primeira pergunta é "para quem estamos projetando?" As perguntas de projeto são o alinhavo do método aplicado ao design, o que muda a perspectiva do processo criativo como mencionado, tal como foi possível comprovar na prática, atestando que este acontece de modo bastante distinto dentro do processo de design de produto. Mas, além dessa, outras perguntas são fundamentais 
O design tem sido definido como uma atividade na qual informações de mercado são transformadas em ideias iniciais - conceitos de design - e, em seguida, em uma configuração específica de materiais e componentes - especificações técnicas - para a fabricação de um novo produto. Em outras palavras, o design industrial/de produto pode ser definido como um processo estratégico que contém o conhecimento acerca de um produto, a partir do qual este pode ser materializado e posicionado no mercado, em resposta às questões básicas "por que" e "como" sobre um produto. (Alpay Er, 2015)

Fazer a forma, no sentido de produzi-la manualmente, não seria exatamente o fazer do design como resultado final, mas como parte do processo de desenvolvimento do produto, o qual não necessariamente será manufaturado pelo designer, e esse é um ponto importante: o designer não necessita executar a peça final projetada. Nesse universo, a forma é resposta a uma pesquisa, análise e elaboração no atendimento a uma necessidade específica, ao universo relacionado a um público específico, e o desenvolvimento do projeto poderia ter como apresentação final seus desenhos e não o objeto em si. Quem faz o projeto de design de um carro não o executa, bem como o projeto de uma geladeira, por exemplo. Nessa fase ao designer caberia o acompanhamento da execução do projeto e possíveis ajustes.

\footnotetext{
O processo artesanal (craftsmanship) termina em um objeto acabado, chamado artefato. No entanto, o designer não cria um objeto acabado sempre. A maior parte dos processos de design terminam com sketches, protótipos e conceitos. E de acordo com Sennett, essa é a principal diferença entre o artesão (craftsman) e o designer. (SENNETT, 2008, apud TEMELTAS, 2017)
}

O confeccionar da peça final entra no campo da artesania ou da arte, sendo que a excelência do processo criativo e da qualidade da execução define a atuação do artífice. A joalheria/ourivesaria é ofício, e dos mais sofisticados, e como tal deve ser valorizado. Bem como a concepção de um adorno pessoal, conceitual em essência, define o trabalho do artista em sua elaboração única, estando aqui o valor da pesquisa formal e dos processos que o levaram ao resultado final. Confundir essas produções com o design dificulta a conceituação e o aprofundamento do estudo desses campos específicos e ricos em seus domínios de conhecimento. 
A distinção crucial é que, nas condições atuais, os objetos de arte são em geral concebidos e feitos por (ou sob a direção de) uma pessoa, o artista, enquanto isso não é verdade para os bens manufaturados. A concepção e a fabricação de sua obra permitem aos artistas considerável autonomia, o que levou à crença comum de que uma das principais funções da arte é dar livre expressão à criatividade e à imaginação. Seja correta ou não essa visão da arte, o fato é que ela certamente não é verdade para o design. (FORTY, 2013)

Seria aqui importante apontar que as principais questões não se dão entre artesanato e design, e como identificá-los ou mesmo separá-los como atividades, mas entre design e produção artesanal como um todo, o que reúne artesanato e artesania.

Estas fronteiras são tênues e é através delas por onde permeiam as principais formas de atuação, porque ao se fazer um artefato, seja manualmente ou industrialmente, o que sugere a diferença entre as duas atividades é o modo como são pensadas, elaboradas, concebidas e desenvolvidas.

Há uma tendência que é preciso apontar em confundir produtos do artesanato e da arte com os de design. Particularmente nos discursos relativos à economia criativa, vê-se a transposição entre essas áreas de modo não criterioso. Sua percepção via senso comum, externo ao campo de estudo do Design, tem permitido a perda de referências entre esses tipos de produção, o que se por um lado unifica e facilita uma abordagem política, por outro traz prejuízos a suas práticas. Tal como se vê na colocação de Edna dos Santos-Duisenberg, assessora do Instituto das Nações Unidas para Treinamento e Pesquisa (UNITAR) e consultora internacional em Economia Criativa e Desenvolvimento:

\footnotetext{
Cabe ressaltar que o design não só lida com a forma e a aparência dos produtos, mas também representa criações funcionais e estéticas expressas de diversas maneiras, como bens ou serviços criativos. A criação de uma joia, a arquitetura de um edifício, o design de um bem industrial como um automóvel ou a concepção de um objeto e decoração de interior único ou produzido em escala são todos produtos de design que incorporam conteúdo criativo, objetivo de mercado e valor econômico e cultural. Design é o setor que mais contribui para a expansão do comercio mundial das indústrias criativas \{...\}" (Duisenberg, 2015).
}

No entanto, a joalheria, pelo que já exposto, possui importantes nuances em seus processos em relação ao design. Confundi-los nos traz profundas questões na prática profissional, uma vez que envolve distintas habilidades e saberes. Embora fique claro que tais atividades estão todas vistas e contempladas na economia criativa dentro do universo da joalheria, mas não do design. 
A artesania é um campo no qual o fazer manual é a base, exigindo domínio e excelência da técnica, e tal como no artesanato, é, em geral, feito por uma só pessoa em todas as suas etapas. E como vimos, no processo de design, este representa uma etapa do processo produtivo como um todo.

Cabe ressaltar que há diferenças percebidas na definição de artesanato no Brasil, distintamente do que é entendido em outros países. Assim, não é possível comparar com definições do que é chamado de craft em inglês, por exemplo, ou craftsmanship, do mesmo modo que não se pode comparar, também, o valor dado ao artesanato na Europa, particularmente, que possui sentido mais próximo do que se propõe chamar de artesania, isto é, um fazer artesanal que pressupõe conhecimentos técnicos específicos de produção, e uma preocupação com a excelência técnica nesse fazer. Este é o ponto principal: a diferença entre design, artesania e artesanato.

Note-se que há autores em inglês que estabelecem uma diferença no uso de craftsman e artisan, em que o primeiro seria o artesão que repete padrões de produção, em escala e estética conhecidos, e o segundo, seria o que cria e produz com técnicas e habilidades especiais. Este seria então, para nós, o entendimento do que seria a artesania, ou o fazer manual baseado em conhecimento e domínio técnico de um tipo de ofício, tal como é a marcenaria, a luteria, a cerâmica e a ourivesaria/joalheria. Observou-se essa conceituação em sites como Study.com (2020) e The Torah Project (2020). Mas não é regra, pois popularmente encontra-se também o uso das duas nomenclaturas como sinônimos em dicionários como no Oxford Dictionary (2020) em que "artisan" é definido como: "a person who does work that needs a special skill, making things with their hands. Synonym: craftsman." (pessoa que faz um trabalho que exige habilidade especial. Sinônimo: "craftsman" - tradução nossa) e "craftsman" no Crambridge Dictionary: "a person who is skilled in a particular craft -Synonym: artisan". (pessoa que possui habilidade em um ofício em especial - Sinônimo - "artisan" - tradução nossa).

Lina Bo Bardi já identificava essa distinção, no livro Tempos de Grossura (1994), com o entendimento de que o objeto do artesanato brasileiro se relaciona mais a práticas de repetição de modelos que se relacionam a culturas regionais, de comunidades, em geral com modelos pré-definidos, materiais locais e acabamentos mais rústicos e de baixo custo. Um exemplo contemporâneo desse artesanato seriam os objetos de adorno feitos com capim dourado, comum no centro do Brasil.

Fato é que joalheiros artesanais no Brasil não querem ser confundidos com artesãos por considerarem o artesanato uma atividade de menor valor, ainda que a joalheria chamada de "joalheria de bancada" seja de fato artesanal, porque feita à mão.

Na maioria das vezes a elaboração formal de um objeto, seja ele de adorno ou outro, quando se dá de forma livre, intuitiva, ou mesmo como resultado de uma experimentação de materiais ou processos, está mais alinhada ao fazer da arte e da artesania, e não do design, principalmente pelo fato de que o design se relaciona com um projeto que em seu processo levará a um resultado esperado e não aleatório. 
Essa é umas das mais importantes premissas dos projetos de design: atender de maneira objetiva a uma demanda específica, uma necessidade em particular, de um público e contexto determinado. Se no processo ocorrerem experimentações, essas serão válidas se o resultado for resposta aos parâmetros iniciais do projeto, gerando um objeto passível de reprodução. E a serialidade seria uma as principais características dos projetos de design: concepção e produção de objetos passíveis de produção seriada.

Essa joia que nasce de forma intuitiva ou artística, não exigindo inclusive técnicas de ourivesaria, estão relacionadas à arte, em seu sentido não só de expressão pessoal, mas de experimentação de materiais e processos, e de leituras do mundo e da cultura em sua contemporaneidade.

É o que comenta Gis Ribeiro (2020), artista joalheira, graduada em artes visuais com várias publicações e prêmios na área, também com graduação em design gráfico, tendo sido diretora de arte na área editorial, corporativa e cultural. Há uns cinco anos passou a dedicar-se à joalheria, com produção bastante significativa no segmento da joalheria contemporânea. Gis a define como um tipo de produção que se baseia na criatividade calcada nos mesmos pressupostos da joalheria de arte, por ser livre, experimental, por quebrar regras na escolha dos materiais, levando em conta as experiências afetivas do artista, a ciência, a filosofia, a arte, a poesia, que são, para ela, os mesmos códigos do pensar e do fazer da produção de arte. Mas que tem um público muito restrito entre os que apreciam e portam essa joia, vista com wearable art, ou uma arte vestível.

A joalheria contemporânea em muito se aproxima do conceito de joalheria de arte, esta mais conceitual, uma vez que basicamente trabalha na direção da valorização do processo criativo e de produção, em detrimento da preciosidade dos materiais utilizados. E, assim, o valor da joia está no processo utilizado por seu criador, tanto na originalidade da criação como na produção. Este tipo de joias tem seu próprio espaço, em geral apresentadas em galerias, estão em contextos distintos das joias comerciais e alcançam um público específico, apreciador e entendedor de seus processos e sua estética. Esse diálogo e validação se dá, então, entre seus pares e não é possível estabelecer comparação qualitativa com outros tipos de produção joalheira, uma vez que estão em universos conceituais bastante diversos.

Mas o fazer manual, artesanal, da joalheria, também se traduz em peças que poderiam ser também mais comerciais. A "joalheria de bancada", como é chamada, inclui o conceito da joalheria autoral que vem imprimir um sentido de personalidade e de exclusividade ao processo criativo e de produção manual, buscando a diferenciação daquela artesanal mais simples, uma vez que é a habilidade na técnica de ourivesaria associada à criação exclusiva que a define. Mas há nesse segmento uma idealização da criação joalheira, ao que muitos identificam como seu design, atribuído ao fato de agregar um certo significado especial à joia, ou uma história a ser contada, de modo a dar a ela e ao processo com que foi concebida, uma aura conceitual de preciosidade. Aqui cumpre distinguir joalheria autoral de design autoral, uma vez que entende-se que este se configura como um engano 
conceitual, uma vez que o design pode ter uma assinatura, mas a autoria pressupõe a impressão de aspectos de características pessoais ao objeto, o que se contrapõe ao sentido do Design, eminentemente voltado a características do público usuário. E essas joias autorais são em geral únicas, o que lhe agrega um atributo especial na assinatura. Esse joalheiro, artífice, tal como o identifica Richard Sennett (2012), é o que busca a perfeição e a originalidade no seu trabalho manual.

Fazer a forma, configurar, no universo das joias de arte, contemporâneas ou mesmo as autorais, percorre um percurso criativo que se distancia daquele do projeto de produto, no sentido de que a criação livre é forma de expressão pessoal, na qual pesa o gosto e a personalidade do autor, e não objetivamente para atender uma demanda específica, de um público específico, com gosto próprio e que define o projeto. Um designer poderá desenvolver até peças que não seriam para seu uso ou mesmo estilo pessoal, mas sua criação terá o perfil do usuário que quer atender.

Um outro aspecto do design de joias está no fato de que muitos profissionais que desenvolvem objetos de adorno artesanalmente, utilizando técnicas de montagem, comuns às bijuterias, mas não de ourivesaria, identificam, também, seu trabalho com essa denominação. Entendem, nesse contexto, que o fato de fazer o arranjo de elementos, a exemplo de reunir em fios as contas de pedras preciosas ou não, pérolas, e outras contas, associados ou não a metais produzidos industrialmente, já definiria o trabalho de design. Esse fazer pertence ao artesanato, tal como é conhecido particularmente no Brasil, remetendo à utilização de materiais já existentes, naturais ou industriais. Na confecção de bijuterias, em que o artesanato aparece de forma mais proeminente, são utilizados, ainda, outros materiais diversos como contas e componentes de plástico, de resina, canutilhos, pedras naturais, cristais, vidros, madeiras, sementes, elementos metálicos em geral, entre outros, na confecção de objetos de adorno elaborados esteticamente de forma também intuitiva, ou repetindo técnicas já utilizadas regionalmente ou incorporadas de outras culturas. Mas uma característica importante desta atividade é a da participação ativa do artesão:

\footnotetext{
A produção artesanal se caracteriza pelo domínio do artesão em todas as fases do processo de produção. Esse processo vai desde a obtenção da matéria-prima, domínio de técnicas de produção e do processo de trabalho até a comercialização do produto. (NIEMEYER, 2007, p.29)
}

Para outros, o artesanato é visto apenas como hobby, utilizando técnicas, além das conhecidas regionalmente, até de grupos distantes, hoje amplamente difundidas pela mídia, rompendo fronteiras culturais.

Assim, será importante definir a configuração, o fazer a forma de artefatos na joalheria, no que se diferencia do que seria o configurar no design de joias como projeto, uma vez que, nesse contexto, é uma resposta projetual a uma demanda específica. 
[...] o conceito de design compreende a concretização de ima ideia em forma de projetos ou modelos, mediante a construção e configuração resultando em um produto industrial passível de produção em série. 0 design estaria então realizando o processo configurativo.

As fases desse processo se denominam design, tanto em nível parcial, como na totalidade do processo. (LÖBACH, 2001)

Analisando-se a produção de joias como um todo na contemporaneidade, observa-se que a fabricação das joias em ouro, em escala industrial tem, nesse momento, demanda reduzida. Hoje a maior procura por projetos criativos estão na produção de folheados, joias com camadas de ouro sobre bases não preciosas, também chamadas de semijoias, (termo que o mercado consagrou e não se logrou mudar até o momento), e na indústria de bijuterias. E para esses segmentos o entendimento de produto é ainda mais significativo, porque se dirigem a públicos mais amplos em camadas específicas, em que a pesquisa formal deve ser bem direcionada, tal como todos os elementos e variáveis envolvidas na produção. Para esses segmentos o valor do material em que são confeccionadas as joias é determinante em relação ao público a que se destina.

\section{Design como projeto de produto ou desenho industrial}

E design de joias seria ou não do campo do Design?

Nesse entendimento de atividade de projeto, ou projetual, é onde são utilizados os métodos aplicados ao desenvolvimento de produtos, entendidos aqui como o desenho industrial, ou design industrial como definido por Löbach (2001) como "toda atividade que tende a transformar em produto industrial passível de fabricação, as ideias para a satisfação de determinadas necessidades de um indivíduo ou grupo". No entanto, recentemente questionou-se a adição do "industrial" ao design, uma vez que sua abrangência contemporaneamente se dá em áreas não materiais também, como aponta Andrea Branzi comentado por Dijon de Moraes (2020):

[...] Andrea Branzi propõe o design como um gesto cultural e o insere dentro de um complexo teorema onde se encontram as questões antropológicas e sociais, a questão do consumo, das transformações dos meios produtivos industriais, das multiplicações de diferentes linguagens, das constantes interatividades e hibridizações possíveis e, por isso mesmo Branzi sempre defendeu que as questões inerentes ao projeto, fossem vistas como sendo parte de um processo maior dentro da cultura projetual. 
O Design como projeto de produto, no que se pode conceber dentro de situações de reprodução industrial e na solução de questões relativas a ela, traduz-se como racionalização, padronização, modulação para a produção seriada industrial, além daquelas que se relacionam a processos de produção como sustentabilidade, custos, gestão e todo o seu valor estratégico no lançamento de produtos.

O campo do design tem afinidade com a gestão porque é uma atividade de resolução de problemas que segue um processo sistemático, lógico e ordenado. (MOZOTA, 2011).

O projeto envolve, desse modo, diferentes elementos em sua elaboração, principalmente no que se relaciona à sua contextualização. 0 Design reúne o conhecimento técnico com o domínio da linguagem formal.

Na joalheria, esse produto, a joia, possui forte valor simbólico e há quem veja na resposta emocional entre objeto e usuário, a expressão dessa função, além daquela de adorno, e nela estaria, assim, explícita a relação entre forma e conteúdo.

Ao se projetar joias tem-se ciência do valor emocional agregado a ela, na maioria das vezes independentemente do valor do material em si, embora materiais preciosos sejam por si só um fator de atração para consumo, afinal, "um diamante é para sempre", disse a DeBeers, a maior produtora mundial de diamantes, nos anos de 1940. Mas a joia marca momentos, rituais de passagem, e é objeto com valor de permanência entre gerações.

Então ao projetar uma joia com a abordagem do design enquanto produto, estamos falando em unir um forte sentido estético, artístico, a inúmeros outros elementos que implicarão no resultado final.

Grandes maisons joalheiras internacionais lançam coleções de joias dentro de contextos muito objetivos, porque um produto de alto valor não pode ser produzido sem a perspectiva de venda, salvo os que são feitos como peças conceituais para firmar a identidade da marca. Assim, os projetos para joalherias serão elaborados considerando todas os fatores como custos, processos, prazos, e o que o relaciona com a marca. Não são aleatórios, são projetados com um resultado esperado. Mas em geral grandes marcas possuem coleções comerciais que proporcionam maior fôlego para sua manutenção. Essas peças serão ainda mais estudadas, porque pretendem atingir públicos determinados, o que irá definir materiais, processos e custos. Então são projetos de design muito bem elaborados.

Este é um ponto importante: na joalheria comercial com etapas industriais, de produção seriada em pequena ou grande escala, há o envolvimento de um grande número de profissionais com expertises definidas, com domínio de conhecimento e habilidades específicas, dentro da divisão de trabalho nas linhas de produção. E isto pode exigir um nível técnico 
bastante apurado. Então os projetos de design deverão atender a essas exigências, o que significa que o designer deverá também conhecer esse universo em profundidade. Nesse caso, não bastaria ser criativo, mas ter o domínio em relação aos elementos que comporão o projeto, inerentes a esse processo.

[...] a produção industrial, inclusive o design, desenvolveu-se até se converter em uma complexa rede que se serve de informações de diversas áreas. A quantidade de informações a que o fabricante tem acesso supera em muito a capacidade de uma memória individual. [...] o processo de design está, portanto, organizado sobre uma base extremamente cooperativa." (FLUSSER, 2007, p.201)

E há aqui um ponto a se destacar: o designer participa de uma das fases do processo de produção da joia, nos processos industriais. Ele desenvolve o projeto de design, mas a parte da confecção é atribuição de outros profissionais. Forty (2013) lembra que:

$\mathrm{Na}$ história de todas as indústrias, o design torna-se necessário como uma atividade separada da produção assim que um único artífice deixa de ser responsável por todos os estágios da manufatura, da concepção à venda.

Isto se dá em relação a todos os segmentos produtivos industriais da joalheria, o de materiais preciosos, o de folheados e o de bijuterias. São setores produtivos que possuem características próprias, tanto nos processos de produção como nos materiais que utiliza.

Uma visita à fábrica Dicini, na época situada em Atibaia, uma das maiores fornecedoras de bijuterias da Avon, responsável pelo desenvolvimento da coleção citada anteriormente, revelou uma linha de produção sofisticada, com dezenas de funcionários nas diferentes fases de produção das bijuterias, com uma organização impecável, dividida através de salas e grandes mesas onde as peças fabricadas em processos industriais aos milhares, iam recebendo acabamentos, colagem de pedras manualmente, bem como a checagem de qualidade final, codificação e embalagem para despacho dos itens. Ao projetar a coleção algumas limitações impostas pelos processos com os quais a empresa trabalhava não eram conhecidas pela autora e, por esse motivo, foram necessários vários ajustes em função da liga de metais e sua maleabilidade, a não cravação de gemas, o uso de pedras artificiais e a tiragem de milhares, quando não milhões de unidades, o que alcança públicos com medidas antropométricas diversas, o que impacta em muitas das ideias que julgou-se viáveis. 
Dependendo do processo industrial utilizado, determinadas propostas são inviáveis tecnicamente, então tem sido essa a razão de tantos desenhos arquivados pelas empresas, porque muitos apresentam belas ideias, mas desvinculadas das realidades do que chamamos "chão de fábrica", ou seja, a realidade da produção industrial. E esses desenhos são em geral apresentados como ilustrações, sem detalhamento ou especificações técnicas. Essa prática tornou-se comum entre os profissionais de criação que são em sua maioria criativos, mas distanciados do conhecimento, tanto do fazer da ourivesaria, como dos processos de produção industrial. e, no caso de folheados e bijuterias, de processos ainda mais específicos.

Desenhar para a fundição em alta fusão é bastante diferente do que pode ser feito em baixa fusão, como também em estamparia, por exemplo. A alta fusão é um processo de produção seriada muito utilizado em joalheria, que consiste na confecção de um modelo inicial que será repetido por fundição em moldes que permitem a reprodução de pequenos detalhes da joia, proporcionando melhor acabamento com maior qualidade. A baixa fusão é também processo de fundição, mas os moldes em borracha vulcanizada não oferecem tão bom acabamento, e alguns detalhes nas joias não são fielmente reproduzidos. Assim, nem todas as peças criadas são possíveis de serem fabricadas em baixa fusão, embora seu custo seja mais baixo do que o processo anterior. É um processo mais utilizado em ligas para bijuterias. E a estamparia é um outro processo no qual o modelo é como que "carimbado" sobre o metal, favorecendo desenhos em chapas, então nem todas as criações são possíveis nesse processo. E há, ainda, outros processos industriais aqui não listados. Assim, para criar, é fundamental conhecer quais os processos utilizados pela indústria que irá fabricar.

A constatação do fato de haver tanta inadequação de propostas apresentadas como design para joias motivou um estudo que está sendo desenvolvido desde o começo do ano de 2020 junto à ABNT, Associação Brasileira de Normas Técnicas, que foi proposto a partir do IBGM, Instituto Brasileiro de Gemas e Metais Preciosos e a AJESP, Associação dos Joalheiros do Estado de São Paulo, com o objetivo de normalizar o desenho técnico de representação de joias, especialmente destinado à produção, particularmente a industrial. A elaboração dessa norma pretende criar parâmetros para a apresentação de desenhos de projetos, que deverão ser apresentados, além da ilustração, em perspectivas, projeções ortogonais em representações ortográficas, escalas, cotagem e especificações em fichas técnicas, entre outros itens a serem definidos. O desenho técnico da joia aparece, assim, como um elo entre as diferentes etapas do projeto.

Entendeu-se que, se for possível utilizar esse padrão de exigência, sendo esses parte das etapas de representação dos estudos concluídos a partir de pesquisas e análises, será possível criar uma cultura de projetos de design dentro da joalheria, através do desenho como sua principal ferramenta, entendendo o Design de joias como uma atividade multidisciplinar de especialização dentro do Design, com contornos fundamentalmente artísticos, mas com cada vez maiores exigências técnicas, particularmente ao 
se considerar processos de reprodução seriada. Esses desenhos são também os que devem ser apresentados para registro de propriedade industrial, a qual se refere a produtos produzidos industrialmente de forma seriada.

Ao se falar em projetos de design espera-se a definição de um método que delineie as fases que o estruturam. A questão do método ainda não foi definida formalmente na joalheria, entendendo a joia como produto. Cada profissional tem desenvolvido sua própria forma de desenvolver o projeto por meio de sua própria prática.

\footnotetext{
O estudo e a aplicação de métodos para o desenvolvimento de projetos de design são tarefas árduas no cotidiano. Por um lado, verifica-se que as diferentes possibilidades abertas à produção, aos produtos e mesmo as opções dos consumidores tornam incomensurável o universo de variáveis a serem consideradas. São tantos e tão diversos os meios de produção e distribuição de produtos, os materiais de fabricação, as idiossincrasias das tendências de moda que não seria exagero supor que cada projeto terá sempre e necessariamente um método próprio. (CIPINIUK, PORTINARI, 2006)
}

Mas, ainda que não se queira adotar um método específico, há que se admitir que existe uma linearidade nessa construção que define fases a serem seguidas, o que pela prática se dá quase que instintivamente, pela lógica da sequência de fases nos processos criativos e de produção. No entanto, os métodos de design auxiliam a quem os conhece, aplicando-os de modo a obter melhores resultados. Assim, será bom conhecer sua estruturação, que obedece à lógica, como um começo, meio e fim, entremeados por diversas possibilidades de etapas de pesquisa e checagem no decorrer do processo.

Destacando que as etapas iniciais de pesquisa são fundamentais no que se refere ao público do nosso cliente, porque é a ele que se dirige nosso produto. $O$ entendimento da empresa contratante, como nosso primeiro público, define as possibilidades das propostas e sua viabilidade técnica no que diz respeito a processo produtivo e capacidade de produção, mão de obra, orçamento, bem como expectativas relacionadas a posicionamento no mercado e vendas. E, posteriormente, as definições do público dessa empresa, como pergunta primeira de projeto: para quem? Uma vez que é para ele a nossa criação.

Estas informações nortearão o projeto, a partir das quais, e só então, serão feitos os desenhos criativos. Sem elas a elaboração de desenhos para venda a empresas se torna um trabalho criativo, desvinculado do processo de design. 
Além disso, no design de produto, todas as especificações são atribuições do designer, como técnico, e assim, o conhecimento das normas de construção no desenho técnico é necessário. 0 designer não pode apenas criar e delegar a outros a função de detalhamento de materiais e medidas, sob pena de ter uma coautoria em seu projeto, uma vez que permitirá interferências que podem alterar a solução formal. Em joalheria lida-se com milímetros e a menor alteração impacta a forma final.

Como comenta Elina Yamamoto (2020), designer da empresa BDG, para esta pesquisa,

\footnotetext{
As informações que correm dentro de uma fábrica são de extrema importância para que o projeto tenha sucesso. Estas informações, como desenho técnico, composição de elementos, tipo de acabamento e medidas, devem estar contidas em uma ficha técnica. Quem faz este trabalho informativo é o designer, portanto é de suma importância ele estar capacitado para este trabalho, caso contrário implica em demora na produção, retrabalho, aumento no custo e até na execução da peça de forma não planejada.
}

A confecção de protótipos em outros materiais distintos do produto final para verificação de aspectos construtivos nem sempre é feita na joalheria, mas pode ser uma possibilidade para estudo da viabilidade técnica e estrutural.

No design de joias essa interferência entre criação e produção tem sido comum, causando muitas vezes problemas por falhas na comunicação, exatamente pela entrega de desenhos apenas ilustrativos e não técnicos. No entanto, no processo da produção em muitos momentos será necessário haver algum tipo de negociação entre eles, de modo a resolver detalhes que facilitem ou viabilizem a produção, mas sempre com a participação indispensável do designer. É função do designer detalhar todo o seu projeto.

\section{Considerações finais}

Após essas considerações, entende-se que há inúmeras nuances dentro da área que vêm até aqui se entrelaçando e permeando, mas que não podem criar um universo a parte do resto da comunidade linguística que envolve o Design como um todo, definindo-o sem critério. E como campo de conhecimento necessitaria ter conceitos claros, evitando ser tão frágil a ponto de permitir interpretações via o universo da linguagem coloquial e do senso comum.

Na verdade, a joalheria contém fronteiras muito permeáveis e de difícil identificação entre essas áreas que têm sido objeto de estudos e debates: a arte, a artesania, o artesanato e o design. Tais discussões têm sido levadas em diversas oportunidades, mas todas resultam infrutíferas ao se 
observar como em tudo o termo design é utilizado, seja como a forma, como o desenho, como o plano ou planificação, mesmo como a montagem de um simples adorno artesanal, tornando, assim, cada vez maior o mal entendido entre todos os profissionais e, particularmente, quando considerado o mercado de trabalho, entre os que os podem contratar como profissionais para o desenvolvimento de produtos em maior escala, ou mesmo no restrito mercado de alta joalheria. E como consequência, infelizmente, temos uma banalização da profissão e sua desvalorização.

Ao se pedir para que cada um desses profissionais que foram elencados nesse artigo se apresentasse sem usar a denominação de designer de joias, ficaria transparente a enorme diferença na atuação de todos eles. Desse modo, o que nos cabe será propor uma reflexão, trazendo esclarecimento sobre o conceito a ela inerente, e apontar denominações mais assertivas a cada uma das atividades no universo da joalheria, visando melhor comunicação entre o grupo e para fora do grupo na relação com o público.

Entre as que identificamos temos a joalheria ou ourivesaria, como o fazer a joia em materiais preciosos; a joalheria autoral, como a criação e produção de joias, com o domínio de todas as etapas; a joalheria de arte e a joalheria contemporânea, que inclui instâncias criativas de expressão pessoal e o artista joalheiro, o que leva a criação e a confecção da joia, ou o adorno, para esse universo de possibilidades da arte; a criação joalheira, por meio do desenho ou outra forma de apresentação de propostas formais que define como o criativo, o profissional; o desenhista de joias, o que faz desenhos de joias, não necessariamente criadas por ele, mas como representação artística de outros criadores para catálogos, vitrines, revistas, exposições, etc.; a joalheria autoral, que identifica um tipo de produção na qual o "autoral" é atributo do tipo de prática joalheira, e as características de estilo pessoal são marcantes, assinando a criação; os modelistas, os que produzem os protótipos por meios manuais ou digitais a partir de desenhos de outros (modelistas 3D); e os designers, ou designers de produto (uma especialização do design) ou ainda desenhistas industriais de joias, os que projetam efetivamente, em sua complexidade, produtos para os segmentos joalheiros visando a produção seriada.

Quanto ao design de joias ser ou não Design, de um modo geral o processo de design está presente em muito pouco do que se denomina design de joias na contemporaneidade. Na maioria das vezes, trata-se de produção artesanal, de artesania, do ofício da joalheria, ou até mesmo de desenhos criativos. Poder-se-ia até dizer que, em alguns casos, o desenvolvimento de ferramentas específicas para atender necessidades de produção por joalheiros estaria mais ligado aos processos de desenvolvimento do Design do que propriamente os trabalhos de criação que assim são identificados. Há pouco pesquisa ligada à inovação em materiais e tecnologias. Há pouco investimento em gestão estratégica e pouquíssima confiança na capacidade do designer em oferecer soluções inovadoras, seja na criação, na gestão do produto e no seu posicionamento para o mercado. Percebe-se, enfim, uma inadequação do uso do termo que compromete o campo do Design. 
Hoje nos vemos emaranhados entre muitos fios que tecem um grande tecido, feito de universos de atuação distintos, entremeados de muitos saberes e habilidades técnicas, das manuais às digitais, nas quais o que os une é apenas a identificação do objeto final: a joia.

Fica a proposta de reflexão: Mas, afinal, a que nos referimos quando falamos em design de joias?

\section{Referências}

ALPAY ER, H. Padrões de desenvolvimento do design industrial no Terceiro Mundo: um modelo conceitual para países recém-industrializados. In: PATROCINIO, Gabriel; NUNES, José Mauro. Design \& Desenvolvimento: 40 anos depois. São Paulo: Blucher, 2015.

ARTISAN In: Oxford learner's Dictionaries. UK. Oxford University Press, 2020. Disponível em: <https://www.oxfordlearnersdictionaries.com/us/definition/english/ artisan>. Acesso em: 04 set. 2020.

BARBOSA, Ana Mae. Redesenhando o desenho: educadores, política e história. São Paulo: Cortez, 2015.

CIPINIUK, Alberto; PORTINARI, Denise B. Sobre métodos de design. In: COELHO, Luiz Antonio L. (org.). Design Método. Rio de Janeiro: PUC-Rio; Teresópolis; Novas Ideias, 2006.

COELHO, Luiz Antonio L. Design Método. Rio de Janeiro: PUC-Rio; Teresópolis; Novas Ideias, 2006.

CRAFTSMAN In: Cambridge Dictionary. UK. Cambridge University Press. 2020. Disponível em: <https://dictionary.cambridge.org/dictionary/english/craftsman.> Acesso em: 04 set. 2020.

DUISENBERG, Edna dos Santos. O papel do design na era do conhecimento. In: PATROCINIO, Gabriel; NUNES, José Mauro. Design \& Desenvolvimento: 40 anos depois. São Paulo: Blucher, 2015.

FAVARO, Henny Aguiar Bizarro Rosa. Design de joias e pesquisa acadêmica: limites e sobreposições. Tese de Doutorado em Arquitetura e Urbanismo. Universidade Presbiteriana Mackenzie. São Paulo, 2013.

FERREIRA, Claudio Lima. $\mathrm{O}$ design contemporâneo brasileiro e sua complexidade. Águas de São Pedro: Livronovo, 2014.

FLUSSER, Vilém. O mundo codificado. São Paulo: Cosac Naify, 2007.

FORTY, Adrian. Objeto de desejo: design e sociedade desde 1750. São Paulo: Cosac Naify, 2013. KRIPPENDORF, Klaus. Design centrado no ser humano. Uma necessidade cultural. In: Estudos em design. Tradução de Gabriela Meirelles. Revisão Técnica da tradução de Lucy Niemeyer. Rio de Janeiro: v.8. n.3, set/des, 2000.

LARICA, Neville Jordan. Formigueiros virtuais. In: COELHO, Luiz Antonio L. (org.) Design Método. Rio de Janeiro: PUC-Rio; Teresópolis; Novas Ideias, 2006.

LEITE, João de Souza. o sentido do design, segundo Joaquim Redig. Anais do $6^{\circ}$ Congresso Internacional de Design da Informação, 2013. Disponível em: <https://www.academia. edu/4697575/O_sentido_do_design_segundo_Joaquim_Redig>. Acesso em: 05 set. 2020.

LÖBACH, Bernd. Design industrial: bases para a configuração de produtos industriais. São Paulo: Blucher, 2001.

MORAES, Dijon. Fenomenologia do design contemporâneo. DAT Journal, São Paulo, v.5, n.2, 2020 . 
MOZOTA, Brigitte Borja de. Gestão do design: usando o design para construir valor de marca e inovação corporativa. Porto Alegre: Bookman, 2011.

NIEMEYER, Lucy, 2007. Design no Brasil: origens e instalação. Rio de Janeiro: 2AB, 2007. NOJIMA, Vera Lucia. Os estudos das linguagens como apoio aos processos metodológicos do Design. In: COELHO, Luiz Antonio L. (org.). Design Método. Rio de Janeiro: PUC-Rio; Teresópolis; Novas Ideias, 2006.

PIMENTEL, Carmen. Comunidades virtuais, comunidades linguísticas. IDIOMA, Rio de Janeiro, no. 29, p. 181-198, 2. Sem. 2015. Disponível em: <http://www.institutodeletras.uerj. br/idioma/numeros/29/Idioma29_a05.pdf> Acesso em: 3 set. 2020.

PROJECT, The Torah. Differences between the artisan \& craftsman. The Torah Project. Disponível em: <https://accartescritta.wixsite.com/torah-project/7-differences-craftsman-artisan>. Acesso em: 06 set. 2020.

RIBEIRO, Gis. Entrevista concedida para esta pesquisa. Entrevistadora: Engracia M. L.C. Llaberia. São Paulo, 2020.

SENNETT, Richard. 0 artífice. Rio de Janeiro: Record, 2012.

SIGAUD, Hugo. A produção do design autoral. Revista clichê. Disponível em: < <http:// www.revistacliche.com.br/2013/02/a-producao-do-design-autoral/>, 2013. Acesso em: 2 set. de 2020.

SILVA, Josué Candido da. Wittgenstein - Pragmática antes da semântica. UOL, 2020. Disponível em: <https://educacao.uol.com.br/disciplinas/filosofia/filosofia-da-linguagem-5-wittgenstein-pragmatica-antes-da-semantica>. Acesso em: 12 ago. 2020.

STUDY. Difference Between Artisan \& Craftsman. Disponível em: <https://study.com/articles/ differencebetweenartisancraftsman. Acesso em: 3 set. de 2020.

TEMELTAS, Handan. Collaboration and exchange between "Craftsman" and "Designer": Symbiosis towards Product Innovation. The Design Journal. Reino Unido: Taylor \& Francis Group, 2017.

YAMAMOTO, Elina. Entrevista concedida para esta pesquisa. Entrevistador: Engracia M. L.C. Llaberia. São Paulo, 2020. 